\title{
The prevalence of malnutrition in spinal cord injuries patients: a UK multicentre study
}

\author{
Samford Wong ${ }^{1,2 *}$, Fadel Derry ${ }^{1}$, Ali Jamous ${ }^{1}$, Shashivadan P. Hirani ${ }^{3}$, George Grimble ${ }^{2}$ and \\ Alastair Forbes ${ }^{2}$ \\ ${ }^{1}$ Department of Nutrition and Dietetics, National Spinal Injuries Centre, Stoke Mandeville Hospital, Aylesbury HP21 8AL, UK \\ ${ }^{2}$ Centre for Gastroenterology and Clinical Nutrition, University College London, London, WC1E 6BT, UK \\ ${ }^{3}$ School of Community and Health Science, City University, London, EC1 OHB, UK \\ (Submitted 9 August 2011 - Final revision received 12 October 2011 - Accepted 15 October 2011 - First published online 15 December 2011)
}

\begin{abstract}
Data on the prevalence of malnutrition among patients with spinal cord injuries (SCI) are lacking. The aim of the present study was to assess nutritional risk at admission, and the status of nutritional support in the UK SCI Centres (SCIC); a cross-sectional, multicentre study in four SCIC. A standardised questionnaire was used and distributed to the participating SCIC. After obtaining informed consent, baseline demographic data, nutritional risk score by the 'Malnutrition Universal Screening Tool', BMI and routine blood biochemistry were collected from every patient admitted to an SCIC. The four SCIC, comprising $48.2 \%$ of the total UK SCI beds, contributed data from 150 patients. On admission, $44.3 \%$ of patients were malnourished or at risk of undernutrition. Nutritional risk was more common in patients with acute high cervical SCI than those with lower SCI $(60.7 v .34 .5 \%)$, and nutritional risk was more common in those with additional complications including ventilatory support (with tracheostomy, $56 \cdot 3 \mathrm{v} .38 \cdot 7 \%$ ). Also, $45 \%$ of patients were at risk of overnutrition $\left(B M I \geq 25 \mathrm{~kg} / \mathrm{m}^{2}\right.$ ). The prevalence of malnutrition in SCI patients admitted to SCIC is higher than national figures focused on general hospitalised patients, indicating that SCI patients are particularly vulnerable to malnutrition. Patients with SCI who have a tracheostomy may need additional attention. Given the potential negative impact of malnutrition on clinical outcomes, an emphasis on mandatory nutrition screening, followed by detailed assessment for at-risk individuals should be in place in the SCIC.
\end{abstract}

\section{Key words: Malnutrition: Spinal cord injuries: Nutrition screening tools}

Recognition of malnutrition and the initiation of adequate nutritional support in hospitalised patients is an important component of in-patient care. Malnutrition among newly hospitalised patients has been reported to be as high as $50 \%$, depending on the hospital setting, patient population and criteria used to define malnutrition ${ }^{(1,2)}$. Malnutrition tends to become more pronounced during hospitalisation and has been shown to be an independent predictor of nosocomial infections $^{(3)}$ and complications ${ }^{(4)}$. Malnutrition is also associated with impaired hospital outcomes, including increased hospital length of stay, and mortality ${ }^{(5-7)}$

The cause of malnutrition in individuals with spinal cord injuries (SCI) is usually multifactorial and includes both the metabolic effects of SCI and underlying medical conditions ${ }^{(8)}$, and reduced nutritional intake ${ }^{(9)}$. There is evidence that additional factors such as age, therapeutic interventions, educational level and socio-economic status may increase the general risk of developing nutritional deficiencies ${ }^{(5)}$. Despite its importance, malnutrition is rarely identified by clinicians working in general hospitals ${ }^{(10)}$ or in SCI Centres (SCIC) $^{(11)}$.

International $^{(12,13)}$ and national ${ }^{(4,7,9)}$ organisations have published guides to promoting good nutritional practices. Nutritional risk screening is an essential first step in the structured process of nutrition care but is not routine in some UK $\mathrm{SCIC}^{(14)}$, and, currently, neither nutrition screening nor dietetic assessment are included in national SCI policy for SCIC ${ }^{(15)}$. A number of nutrition screening tools have been developed and validated for hospitalised adults, such as the 'Malnutrition Universal Screening Tool' ('MUST') ${ }^{(16)}$, but to date, peerreviewed validated screening tools suitable for specialist use in SCI patients are not available.

The present multicentre study aimed to establish the prevalence of malnutrition in hospitalised SCI patients

Abbreviations: MUST, Malnutrition Universal Screening Tool; SCI, spinal cord injuries; SCIC, spinal cord injuries centres.

*Corresponding author: S. Wong, fax +4401296 315049, email samford.wong@ucl.ac.uk 
Table 1. American Spinal Injury Association (ASIA) impairment classification of the participants*

\begin{tabular}{lccccccr}
\hline & \multicolumn{7}{c}{ Level of SCI } \\
\cline { 2 - 7 } & & Cervical & Thoracic & Lumbar & Sacral & Total & $\%$ \\
\hline AIS & A & 23 & 40 & 7 & 0 & 70 & $50 \cdot 4$ \\
AIS & B & 4 & 3 & 3 & 0 & 10 & $7 \cdot 2$ \\
AIS & C & 14 & 8 & 6 & 0 & 28 & $20 \cdot 1$ \\
AIS & D & 16 & 8 & 6 & 1 & 31 & $22 \cdot 3$ \\
Total & & 57 & 59 & 22 & 1 & $139 \dagger$ & \\
$\%$ & & 41.1 & $42 \cdot 4$ & $15 \cdot 8$ & 0.7 & & \\
\hline
\end{tabular}

SCI, spinal cord injury; AIS: ASIA Impairment Scale.

* $41.1 \%$ Tetraplegia; $58.9 \%$ paraplegia; $50.4 \%$ complete SCl; $49.6 \%$ incomplete $\mathrm{SCl}$

†Eleven missing neurology and AIS because re-admitted patients were not routinely measured.

admitted to UK SCIC by using a validated generic nutrition screening tools, the 'MUST' for undernutrition, and BMI for overnutrition. The secondary objectives of the study were to assess where co-existing medical conditions may increase the risk of malnutrition in SCI patients.

\section{Methods}

\section{Centre recruitment}

Nutritional support practitioners (dietitians) from each SCIC ( $n$ 11, total beds: $n$ 454) in the UK were provided with a study protocol and invited to participate. In July 2009, a coordinator and local investigator from each centre wishing to participate were identified (four SCIC, total beds: $n$ 224). The study protocol was discussed and reviewed during a $1 \mathrm{~d}$ meeting in June 2009. The chief investigator (S. W.) then trained the local investigator responsible for conducting the study at the other institutions. The study began on 1 July 2009 and terminated in March 2010.

\section{Data collection}

SCI patients with $\geq 18$ years of age admitted to the SCIC were invited to participate in the study within $96 \mathrm{~h}$ of admission. Patients were excluded if they did not have SCI, were admitted for day care, were unable to give informed consent due to cognitive impairment or had suffered acute stroke.

\section{Definition of malnutrition}

Risk of undernutrition was calculated from MUST scores ${ }^{(16)}$ Patients who had scores $\geq 1$ were considered nutritionally at risk. Overnutrition was defined using the conventional BMI cut-off of greater than $25 \mathrm{~kg} / \mathrm{m}^{2}$ for overweight and greater than $30 \mathrm{~kg} / \mathrm{m}^{2}$ for obese.

A post-interview dietetic assessment using available clinical, nutritional and biochemical information was carried out by the local investigator. This included the measurement of baseline demographics and clinical characteristics of patients admitted to the SCIC (including age, sex, level of spinal cord injury, completeness of injury, American Spinal Injury Association Impairment Scale score, reason for SCI, weight and height) and

Table 2. Nutritional risk according to patients' demographic data and cause of spinal cord injuries

\begin{tabular}{|c|c|c|c|}
\hline & Number of patients & At-risk patients ('MUST' score $\geq 1$ ) & $\%$ \\
\hline \multicolumn{4}{|l|}{ Admission type ( $n$ 149) } \\
\hline New admission & 96 & 44 & $45 \cdot 8$ \\
\hline Re-admission & 53 & 19 & 35.8 \\
\hline \multicolumn{4}{|l|}{ Age $(n 148)$} \\
\hline$<60$ years old & 109 & 47 & 43.2 \\
\hline$>60$ years old & 38 & 16 & $42 \cdot 1$ \\
\hline \multicolumn{4}{|l|}{ Cause of injury $(n 111)$} \\
\hline RTA & 30 & 15 & 50 \\
\hline Domestic & 30 & 19 & $63 \cdot 3$ \\
\hline Sport & 10 & 5 & 50 \\
\hline Assault & 6 & 2 & 33.3 \\
\hline Non-traumatic & 33 & 12 & $36 \cdot 4$ \\
\hline \multicolumn{4}{|l|}{ Social history } \\
\hline Smoker ( $n$ 98) & 45 & 28 & $62 \cdot 2$ \\
\hline Alcohol user (of 99) & 67 & 34 & 50.7 \\
\hline \multicolumn{4}{|l|}{ Ethnicity } \\
\hline Caucasian & 131 & 33 & $25 \cdot 2$ \\
\hline Asian & 10 & 2 & $20 \cdot 0$ \\
\hline Afro-Caribbean & 8 & 1 & $12 \cdot 5$ \\
\hline Other & 1 & 0 & 0 \\
\hline \multicolumn{4}{|l|}{ Disease severity } \\
\hline Mechanical ventilated $(n$ 147) & 16 & 9 & $56 \cdot 3$ \\
\hline Non-ventilated & 111 & 43 & 38.7 \\
\hline History of ICU stay ( $n$ 146) & 47 & 27 & $57 \cdot 4$ \\
\hline No history of ICU stay & 93 & 36 & 38.7 \\
\hline Presence of pressure ulcers ( $n$ 147) & 49 & 26 & 53.1 \\
\hline No pressure ulcers & 87 & 57 & 65.5 \\
\hline Artificial nutritional support ( $n$ 146) & 14 & 14 & 100 \\
\hline Non-artificial nutritional support & 132 & 48 & $36 \cdot 4$ \\
\hline
\end{tabular}

MUST, Malnutrition Universal Screening Tool; RTA, road traffic accident; ICU, intensive care unit. 
Table 3. BMI distribution according to spinal cord injuries (SCl) centres*

\begin{tabular}{|c|c|c|c|c|c|c|}
\hline \multirow[b]{3}{*}{ BMI $\left(\mathrm{kg} / \mathrm{m}^{2}\right)$} & \multicolumn{6}{|c|}{ Level of SCl } \\
\hline & \multicolumn{2}{|c|}{ Tetraplegia } & \multicolumn{2}{|c|}{ Paraplegia } & \multirow[b]{2}{*}{ Total } & \multirow[b]{2}{*}{$\%$} \\
\hline & Complete & Incomplete & Complete & Incomplete & & \\
\hline$<18.5$ & 4 & 2 & 4 & 1 & 11 & 7.9 \\
\hline $18 \cdot 5-22$ & 4 & 12 & 14 & 2 & 32 & $22 \cdot 9$ \\
\hline $22-27$ & 11 & 12 & 16 & 18 & 57 & $40 \cdot 7$ \\
\hline $27-30$ & 1 & 4 & 5 & 10 & 20 & 14.3 \\
\hline$>30$ & 3 & 6 & 6 & 5 & 20 & 14.3 \\
\hline Total & 22 & 33 & 42 & 35 & 140 & \\
\hline
\end{tabular}

*Overweight: $\mathrm{BMI}>22 \mathrm{~kg} / \mathrm{m}^{2}, 69.3 \%$; $\mathrm{BMl}>25 \mathrm{~kg} / \mathrm{m}^{2}, 45.0 \%$. Obese: $\mathrm{BMl}>27 \mathrm{~kg} / \mathrm{m}^{2}, 28.5 \%$; $\mathrm{BMI}>30 \mathrm{~kg} / \mathrm{m}^{2}, 15 \cdot 3 \%$.

routine blood tests for urea and electrolytes, total protein and albumin concentration, $\mathrm{Hb}$, and C-reactive protein. Information about nutrition factors, such as route of nutrition; nutrient intake, as estimated by food record charts (nil by mouth, less than half, half, more than half and all eaten); interruptions; and supplementation of nutrition (use of oral nutritional supplements and artificial nutritional support) was collected. In addition, clinical data, including the presence of co-morbidities, use of mechanical ventilation, history of intensive care unit stay and number of medications, were recorded.

Each study centre was coded for identification, and after local data collection, each patient was coded, before anonymous data transfer to the data-handling centre.

The chief investigator and a clinical adviser were available throughout the study period for questions regarding the study protocol or data entry.

\section{Ethical consideration}

The study was conducted according to the guidelines laid down in the Declaration of Helsinki and the study received ethical approval from the National Research Ethics Committee (ref: 08/H0605/83); all centres received approval from their local research and development departments. Written informed consent was obtained from patients before data collection.

\section{Statistical analysis}

Differences between independent groups were assessed using Student's $t$ test, the Mann-Whitney $U$ test, ANOVA or the Kruskal-Wallis test, depending on the distributions of the data. Differences in proportions were analysed via the $\chi^{2}$ test, with statistical significance set at $5 \%(P=0 \cdot 05)$. All statistical tests were conducted using Minitab Statistical Software (version 15.0; Minitab, Inc.).

\section{Results}

Of the eleven SCIC, four agreed to participate in the study. Between them, they represented $48 \cdot 2 \%$ (224 out of 465 ) of the spinal injury beds in the UK.

For the analysis, 150 (64\% new admissions) aged 18-88 years (median 44 years, 30.7\% female) were assessed, and their demographic data and nutritional risk are summarised in Tables 1 and 2, respectively.

Of the ninety-one new admissions, the median age at onset of SCI was 47 years (inter-quartile range 33, 61), and it took a median of $36 \mathrm{~d}$ for patients to be transferred to an SCIC.

The median duration of SCI for re-admissions was 4 years, with a range of 6.5 months to 46 years.

Of the 150 patients included in the analysis, 93.3\% (140 out of 150) could be screened using the MUST. At the time of hospital admission, $40.0 \%$ (fifty-six out of 140) were found to be nutritionally 'at risk' (MUST score $\geq 1$ ), and $21.4 \%$ (thirty out of 140) were assessed as being 'at high risk' of malnutrition (MUST score $\geq 2$ ). Table 3 summarises the distribution of BMI according to SCI level, and Table 4 shows the percentages of patients at nutritional risk at the different SCIC.

The highest prevalence of nutritional risk was found in groups with prior intensive care unit stays $(57 \cdot 4 \mathrm{v} .38 .7 \%$;

Table 4. Malnutrition risk distribution according to spinal cord injuries centres*

\begin{tabular}{|c|c|c|c|c|c|c|c|c|}
\hline \multirow[b]{3}{*}{ Centres } & \multirow{3}{*}{$\begin{array}{l}\text { Number of } \\
\text { patients }\end{array}$} & \multirow{3}{*}{$\begin{array}{l}\text { Percentage } \\
\text { screened }\end{array}$} & \multirow{2}{*}{\multicolumn{2}{|c|}{$\begin{array}{c}\text { Risk according to the } \\
\text { MUST: } \\
\text { 'MUST' }>1\end{array}$}} & \multicolumn{4}{|c|}{ Risk according to BMI } \\
\hline & & & & & \multicolumn{2}{|c|}{$\mathrm{BMI}>22 \mathrm{~kg} / \mathrm{m}^{2}$} & \multicolumn{2}{|c|}{$\mathrm{BMI}>25 \mathrm{~kg} / \mathrm{m}^{2}$} \\
\hline & & & $\%$ & $n$ & $\%$ & $n$ & $\%$ & $n$ \\
\hline 1 & 102 & $90 \cdot 2$ & $46 \cdot 7$ & $43 / 92$ & 67.4 & $62 / 92$ & $45 \cdot 6$ & $42 / 92$ \\
\hline 2 & 23 & 100 & $17 \cdot 4$ & $4 / 23$ & $78 \cdot 3$ & $18 / 23$ & $34 \cdot 7$ & $8 / 23$ \\
\hline 3 & 14 & 100 & $42 \cdot 8$ & $6 / 14$ & $64 \cdot 3$ & $9 / 14$ & $42 \cdot 8$ & $6 / 14$ \\
\hline 4 & 11 & 100 & $27 \cdot 3$ & $3 / 11$ & $72 \cdot 7$ & $8 / 11$ & 63.6 & $7 / 11$ \\
\hline Total & 150 & $93 \cdot 3$ & $40 \cdot 0$ & $56 / 140$ & $69 \cdot 2$ & $97 / 140$ & 45 & $63 / 140$ \\
\hline
\end{tabular}

MUST, Malnutrition Universal Screening Tool.

*At risk of undernutrition: 'MUST' $\geq 1$; overweight: BMI $\geq 22 \mathrm{~kg} / \mathrm{m}^{2}$. 


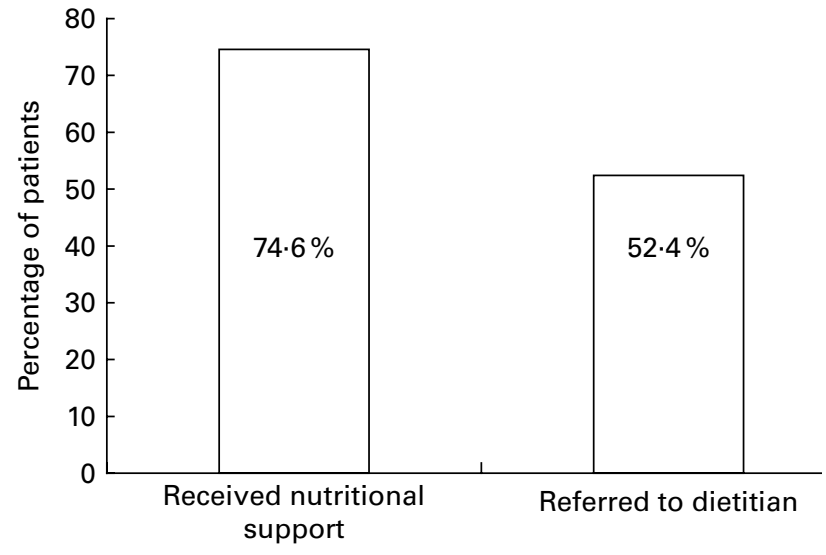

Fig. 1. Percentage of patients at nutritional risk who received nutritional support and dietetic referral: forty-seven out of sixty-three nutritionally at-risk patients received nutritional support and thirty-three out of sixty-three nutritionally at-risk patients were referred to dietitians.

$P=0.035)$, mechanical ventilation $(56.3$ v. $38.7 \% ; P=0.183)$ and artificial nutritional support at the time of arrival (100 $v$. $36.4 \% ; P<0 \cdot 001)$. Nutritional risk distribution, according to age group, is presented in Table 2

In the present study, we found that nutritional risk showed no significant difference with increased age $(43.2$ v. $42 \cdot 1 \% ; P=0.913)$.

Only $74.6 \%$ (forty-seven out of sixty-three) of nutritionally at-risk patients received nutritional support, and only $52.4 \%$ (thirty-three out of sixty-three) were referred to dietitians (Fig. 1). Of the forty-seven patients who received nutritional support, $40 \cdot 4 \%$ (nineteen out of forty-seven) received oral nutritional support, while $34.0 \%$ (sixteen out of forty-seven) received artificial nutritional support. Of the sixteen patients who received artificial nutritional support, $62.5 \%$ (ten out of sixteen) received nasogastric feeding, 31.2\% (five out of sixteen) received gastrostomy feeding and $6.3 \%$ (one out of sixteen) received parenteral nutrition (Fig. 2).

Compared with 'no-risk' patients (MUST score $=0$ ), at-risk patients (MUST score $\geq 1$ ) were found to have significantly lower concentrations of total protein, albumin, $\mathrm{Hb}$, creatinine and $\mathrm{Mg}$, with lower BMI and less appetite. In addition, 'at-risk' patients were found to be receiving more prescribed medications (Table 5)

\section{Discussion}

This is the first study to show clearly that malnutrition, including both undernutrition and overnutrition, is common in patients admitted to SCIC in the UK. The results are worse than those reported in unselected in-patients ${ }^{(1,2,6,7)}$, suggesting that SCI patients are a particularly vulnerable group.

The percentage of 'at risk of undernutrition' patients ranged from $17 \cdot 4$ to $46.7 \%$, reflecting the heterogeneity of the different patient groups. Indeed, there are several factors that could contribute to this observed rate of malnutrition. The nutritional needs and management of patients who have sustained SCI and are still recovering from the acute trauma, and of those who are stable and undergoing rehabilitation are quite different ${ }^{(17,18)}$. Increased or decreased energy intake and requirements depend on SCI phase $\mathrm{s}^{(8,9,17,18)}$, age ${ }^{(9)}$ and mode of ambulation. Weight loss is common during the acute ${ }^{(8)}$ and early rehabilitation phases of $\mathrm{SCI}^{(8,17)}$. On the other hand, there is reduced activity, and muscle mass is lost, with an attendant decrease in energy requirements. In the long term, there is a tendency for people with SCI to gain weight $^{(9,18)}$ because of enforced inactivity.

A high proportion of at-risk patients were identified in one SCIC. This was probably due to the subjective criteria of the weight-loss scoring (step 2 of the 'MUST'), as it is not uncommon for patients to report weight loss post-SCI, and on those grounds, a high proportion of patients at that particular centre were classified as being at nutritional risk. Only one SCIC was not able to weigh patients until they were mobilised. As a result, the researcher used estimated weight, and, therefore, some weights may have been inaccurate. Similarly, lower diagnostic accuracy is expected when the nutrition screening tools is completed by non-dietitians. In addition, a majority of participants were fit and well before SCI, and, therefore, the assessment of weight-loss scores was purely based on recall and may have been over-reported.

Adjusted BMI cut-offs of $22 \mathrm{~kg} / \mathrm{m}^{2}$ for overweight and $27 \mathrm{~kg} / \mathrm{m}^{2}$ for obese have been proposed for SCI individuals ${ }^{(19)}$ To use this would mean that an extra $24 \%$ (thirty-four) of individuals are potentially at risk of overnutrition. Given the long-term adverse consequences of obesity, future efforts should make weight management an integral part of SCI rehabilitation and implementation at SCIC.

Several reports have indicated that a minority of in-patients at risk of malnutrition actually receive appropriate nutrition while hospitalised. The extent to which nutritional support is offered to at-risk patients has been reported to be as low as $14 \cdot 7 \%{ }^{(2)}$. In the present study, $52 \cdot 4 \%$ of at-risk patients (thirty-three out of sixty-three) were referred to dietitians for nutritional assessment and nutritional intervention. It is likely that the present study population had a higher degree of nutritional support, due to

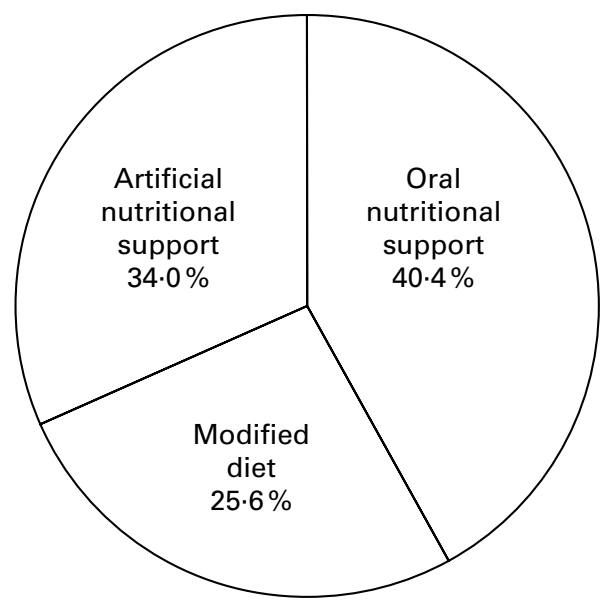

Fig. 2. Mode of nutritional support. Of the sixteen patients who received artificial nutritional support, ten $(62.5 \%)$ received nasogastric feeding; five $(31.2 \%)$ received gastrostomy feeding and one $(6.3 \%)$ received parenteral nutrition. 
the nutritional interest of local investigators who participated in the study, but even in this context, malnutrition is still underrecognised and undermanaged.

In conducting the present multicentre study, we chose to use the 'MUST' because it has been validated in large patient populations and is accepted as a standard tool for nutritional risk assessment ${ }^{(4)}$. A training meeting was conducted before the study. While the majority of local investigators (three out of four) were familiar with the 'MUST', those not familiar (from one centre) were able to implement the screening tool independently after $3 \mathrm{~h}$ of training. Telephone calls and email communications made throughout the present study, and at biannual steering group meetings, identified few and minor problems regarding implementation.

The strengths of the study were its inclusion of almost half the spinal beds in the UK (49\%, 224 out of 456 beds) and its relatively broad representation of different geographical regions, when compared with single-centre studies. However, since the study relied on voluntary data submission from only four centres, we were unable to determine whether our observations applied to all SCI patients in the UK. We call for further studies to assess the prevalence of malnutrition in SCI patients. In addition, different centres measure different sets of blood tests on admission; some blood parameters, such as Mg and Ca levels, may not be measured routinely, and missing values may have compromised our conclusions.

The present study suggests the urgent necessity of reviewing current nutritional resource allocation and policy in UK SCIC ${ }^{(20)}$. It sends a strong message to SCIC managers and commissioners about the need to review implementation of the resolution on Food and Nutritional Care in Hospitals, adopted by the Committee of Ministers of the Council of Europe in November $2003^{(13)}$.

\section{Conclusion}

The prevalence of malnutrition in SCI patients admitted to SCIC is higher than national figures for general hospitalised patients, indicating that SCI patients are particularly vulnerable to malnutrition. Patients with SCI who have tracheostomies may need additional attention. Given the potential negative impact of malnutrition on clinical outcomes, SCIC should place additional emphasis on mandatory nutritional screening, followed by detailed assessment of at-risk individuals.

The authors are pleased to acknowledge their support from the UK National Institute for Health Research via its funding of the University College London, UCLH Biomedical Research Centre. The authors would like to thank the staff of the different SCIC for their kind support in the different hospitals participating in the study. The study group included: Professor John Reilly, University of Glasgow; Joan Gandy, The British Dietetic Association; Anthony Twist, The Robert Jones and Agnes Hunt Orthopaedics and District Hospital, Oswestry, UK; Philippa Bearne, Salisbury District Hospital, Salisbury, UK; Angela Gall and Judith Susser, Royal National Orthopaedic Hospital, Stanmore, UK. The authors' contributions are as follows: S. W. contributed to protocol development, data collection, data analysis and manuscript preparation; F. D. 
was involved in protocol development, clinical supervision and manuscript revision; A. J. contributed to clinical supervision and manuscript revision; S. P. H. was involved in statistical supervision and manuscript revision; G. G. contributed to academic supervision and manuscript revision; A. F. acted as the guarantor, and was involved in academic supervision and manuscript revision. Conflict of interest: this study was funded by an unrestricted grant from Abbott Nutrition. Part of the study data was presented at the International Spinal Cord Society annual meeting in June 2011 and the UK Nutrition Society annual meeting in July 2011.

\section{References}

1. Kyle UG, Pirlich M, Schuetz T, et al. (2003) Prevalence of malnutrition in 1760 patients at hospital admission: a controlled population study of body composition. Clin Nutr 22, 473-481.

2. Rasmussen HH, Kondrup J, Staun M, et al. (2004) A prevalence of patients at nutritional risk in Danish hospitals. Clin Nutr 23, 1009-1015.

3. Schneider SM, Veyers P, Pivot X, et al. (2004) Malnutrition is an independent factor associated with nosocomial infections. Br J Nutr 92, 105-111.

4. National Institute for Health and Clinical Excellence (2006) Nutrition Support in Adults: Oral Nutrition Support, Enteral Tube Feeding and Parenteral Nutrition. London: NICE.

5. Naber TH, Schermer T, de Bree A, et al. (1997) Prevalence of malnutrition in nonsurgical hospitalised patients and its association with disease complication. Am J Clin Nutr 66 , $1232-1239$.

6. Correia MI \& Waitzberg DL (2003) The impact of malnutrition on morbidity, mortality, length of hospital stay and costs evaluated through a multivariate model analysis. Clin Nutr 22, 235-239.

7. British Association of Parenteral and Enteral Nutrition (BAPEN) (2010) Malnutrition Matters: Meeting Quality Standards in Nutritional Care. Redditch, Worcs: BAPEN.

8. Cheshire DJE \& Coats DA (1966) Respiratory and metabolic management in acute tetraplegia. Paraplegia 4, 1-23.

9. Multidisciplinary Association of Spinal Cord Injury Profession (2010) Management of the Older Person with A New Spinal Cord Injury. www.mascip.co.uk/guidelines.aspx
10. Roubenoff R, Roubenoff RA, Preto J, et al. (1987) Malnutrition among hospitalised patients: a problem of physician awareness. Arch Intern Med 147, 1462-1465.

11. Wong SS, Derry F, Forbes A \& Grimble G (2011) Nutrition knowledge among staff working in UK specialist spinal injuries centre. Proc Nutr SOC 69, E530.

12. Jensen G, Mirtallo J, Compher C, et al. (2010) Adult starvation and disease-related malnutrition: a proposal for etiology-based diagnosis in the clinical practice setting from the international consensus guideline committee. Clin Nutr 29 , $151-153$.

13. Council of Europe Committee of Ministers (2003) Resolution RESAP on Food and Nutritional Care in Hospitals. https:// wcd.coe.int/ViewDoc.jsp?id $=85747$

14. Wong SS, Derry F, Gandy J, et al. (2010) A national, multi centre audit to assess resources allocation and nutritional practice in the spinal injury units. Proc Nutr Soc 68, OCE1, E132.

15. Joint Standard Development Groups of the South England Review Group (2003) Standards for Patients Requiring Spinal Cord Injury Care. http://www.mascip.co.uk/standardssciPDF (accessed April 2010).

16. Elia M (2003) Screening for Malnutrition: A Multidisciplinary Responsibility. Development and Use of the Malnutrition Universal Screening Tool (MUST) for Adults. Redditch, Worcs: BAPEN.

17. Consortium for Spinal Cord Medicine (2008) Early Acute Management in Adults with Spinal Cord Injury: A Clinical Practice Guideline for Health-care Providers. Washington, DC: Paralyzed Veterans of America.

18. Royal College of Physicians (2008) Chronic Spinal Cord Injury: Management of Patients in Acute Hospital Setting: National Guidelines. London: Royal College of Physicians.

19. Laughton GE, Buchholz AC, Martin Ginis KA, et al. (2009) Lowering body mass index cutoffs better identifies obese persons with spinal cord injury. Spinal Cord 47, 757-762.

20. Joint Standard Development Groups of the South England Review Group (2010) Standard for Patients Requiring Spinal Cord Injury Care. http://www.secscg.nhs.uk/EasySiteWeb/getresource.axd?AssetID=99975\&type=full\&servicetype $=$ Attachment $\quad$ (accessed 20 November 2010; Revised 2010). 